\title{
Caracterización de propóleos provenientes del municipio de Caldas obtenido por dos métodos de recolección
}

\section{Characterization of propolis from municipality of Caldas obtained through two collection methods}

\author{
Julián Martínez G, ${ }^{1}$ M.Sc, Carlos Garcia $P^{1}$ Ph.D, Diego Durango R, ${ }^{1}$ M.Sc, \\ Jesús Gil G, 1,2* Ph.D.
}

\begin{abstract}
1Universidad Nacional de Colombia, Facultad de Ciencias, Escuela de Química, Grupo de Química de los Productos Naturales y los Alimentos, Medellín, Colombia. 2 Universidad Nacional de Colombia, Facultad de Ciencias Agropecuarias, Departamento de Ingeniería Agrícola y Alimentos. Medellín, Colombia. *Correspondencia: jhgilg@unal.edu.co.
\end{abstract}

Recibido: Mayo de 2010; Aceptado: Junio de 2011.

\begin{abstract}
RESUMEN
Objetivo. Determinar las características fisicoquímicas y la actividad antimicrobiana de propóleos de Apis mellifera, provenientes del municipio de Caldas, obtenidos por dos métodos de recolección. Materiales y métodos. Se utilizaron dos métodos de recolección: de raspado y trampa plastica. Se estableció el contenido de cera, ceniza, material insoluble y resina de los propóleos crudos. Al extracto etanólico de los propóleos se les determinó el perfil cromatográfico (GC-MS) y el espectro UV; además, se evaluó la actividad antimicrobiana in vitro frente a hongos (Aspergillus sp., Penicillium sp., Colletotrichum acutatum y C. gloesporioides), y bacterias (Salmonella tiphy, Bacillus subtilis, Staphylococcus aureus y Escherichia coli). Resultados. El material obtenido mediante malla matrizada presentó un perfil químico amplio, buena actividad antimicrobiana y mejores parámetros de calidad, de acuerdo con estándares establecidos por normas internacionales que los propóleos obtenidos por el método de raspado. Además, pudo observarse que la acción antimicrobiana de los propóleos fue dependiente de la concentración del extracto y del hongo o bacteria evaluada. Conclusiones. La composición química y la actividad antibacteriana y antifúngica de los propóleos están relacionadas con el método de recolección. El presente estudio aporta información para la selección de la técnica de cosecha del propóleo de acuerdo con la aplicación que se desee dar.
\end{abstract}

Palabras clave: características, propiedades antibacteriales, propiedades fisicoquímicas, propóleos (Fuente:CAB). 


\begin{abstract}
Objective. To determine the physicochemical characteristics and the antimicrobial activity in propolis from Apis mellifera, collected in the municipality of Caldas through two harvesting procedures. Materials and methods. Two harvesting methods were used: Scraping and plastic screens. The wax, ash, insoluble material and resin in raw propolis contents were established. The chromatographic profile (GC-MS) and the UV spectra of the ethanolic extract of propolis were recorded. In addition, In vitro antimicrobial activity of ethanolic extract of propolis was evaluated for fungi (Aspergillus sp., Penicillium sp., Colletotrichum acutatum and C. gloeosporioides) and bacteria (Salmonella tiphy, Bacillus subtilis, Staphylococcus aureus and Escherichia coli). Results. The material obtained through the use of the plastic screen presented a broad chemical profile, high antimicrobial activity and better quality parameters compared to the propolis obtained by scraping, according with international regulations. Moreover, the study indicated that the antimicrobial action of this propolis is dependent on the concentration of the extract used and the microorganism evaluated. Conclusions. The chemical composition and antibacterial and anti-mycotic activity of propolis is related to the harvesting method. This study provides information for selecting the propolis harvesting method, according to its desired application.
\end{abstract}

Key words: antibacterial properties, characteristics, physicochemical properties, propolis (Source: $C A B$ ).

\section{INTRODUCCIÓN}

El propóleos es una sustancia obtenida por las abejas mediante la adición de cera y secreciones salivares al material gomoso o balsámico, que recolectan de las hojas y grietas en la corteza de numerosas especies vegetales. Además de ser el material de construcción de la colmena, el propóleos es empleado por las abejas como "arma química" contra los microorganismos patógenos; la presencia de esta sustancia al interior de la colmena proporciona un ambiente inadecuado para el crecimiento de bacterias y otros microorganismos. A este producto apícola le atribuyen efectos antiinflamatorios (1), inmunomodulatorios (2), hepatoprotectores (3), anticariogénicos (4), carcinoestáticos, (5), antimicrobianos (6), antivirales (7), antioxidantes (8) y antifúngicos (9); con aplicaciones a micosis dermatológica restringida casi exclusivamente al género Candida (10). Sin embargo, en alimentos son escasos los estudios relacionados con el control de hongos fitopatógenos o como posible preservante $(9,11)$.

El propóleos es una mezcla compleja de sustancias naturales que contiene una gran variedad de compuestos químicos (12); entre las moléculas farmacológicamente activas se destacan flavonoides y ácidos fenólicos y sus ésteres (13). No obstante, en muestras provenientes de países del trópico, que también presentan una actividad biológica similar, se han encontrado moléculas del tipo terpenoide, derivados prenilados de ácidos $\rho$-cumáricos, lignanos, y benzofenonas preniladas, lo cual sugiere que la actividad es debida a la combinación y sinergias de diferentes compuestos (14). La composición del propóleos depende en gran medida del origen botánico (15), especie de abeja (14), época y método de recolección. Con respecto a este último factor, aunque existen varios métodos de recolección de este material, se han utilizado principalmente el método tradicional de raspado y el empleo de mallas plásticas. Generalmente, del primero se obtienen propóleos con gran cantidad de impurezas (16) y contaminantes, como metales pesados (plomo, hierro y cobre) que pueden provenir de la atmósfera o ser incorporados en la cosecha y la extracción (17). Por su parte los propóleos en bruto obtenidos de las mallas, normalmente presentan mejor calidad, con pocas impurezas y libres de contaminantes (18). Como resultado de la diversidad en la composición química de este producto apícola y el empleo generalizado en la industria, se ha hecho necesario el control de calidad y la normalización del propóleos crudo y sus productos. Con este fin, se han establecido metodologías de trabajo en diferentes normas internacionales, entre las que se incluyen el reglamento técnico para la fijación de identidad y calidad de propóleos del Ministerio de Agricultura de Brasil (19).

En el presente trabajo se evaluó la composición química y la actividad antimicrobiana de los propóleos provenientes del municipio de Caldas (Antioquia, Colombia), colectados en un mismo apiario por los métodos: tradicional de raspado y malla matrizada. 


\section{MATERIALES Y METODOS}

Sitio de estudio y obtención de propóleos. Los propóleos se obtuvieron en el apiario La Alianza del municipio de Caldas (AntioquiaColombia), ubicado a $22 \mathrm{~km}$ de Medellín y a una altura de 1759 msnm. Las muestras se colectaron en época de verano, durante los meses de junio-julio de 2007, por los métodos de raspado (CR) y malla plástica (CM) (malla flexible con orificio romboide de $3 \times 3 \mathrm{~mm}$ ) hasta obtener una muestra representativa del apiario y en cantidad suficiente para los análisis. La vegetación predominante alrededor de los apiarios consiste de Eucalyptus glóbulos, Pinus patula, Cupressus lusitánica Miller y rastrojo nativo. El material se almacenó bajo refrigeración y en ausencia de luz, en el laboratorio de Productos Naturales de la Universidad Nacional de Colombia sede Medellín. Previo al análisis, las muestras se trituraron y homogenizaron.

Preparación de los extractos. Se pesaron $30 \mathrm{~g}$ de los propóleos crudos, los cuales se sometieron a extracción exhaustiva con etanol destilado del $96 \%(3 \times 100 \mathrm{~mL})$ durante $48 \mathrm{~h}$ a temperatura ambiente y en ausencia de luz. Seguidamente, la mezcla se centrifugó a 3000 rpm durante 10 min y se filtró por gravedad. Al filtrado obtenido se le adicionó $10 \mathrm{~mL}$ de agua destilada y se dejó en refrigeración hasta precipitar las ceras (12 h, aproximadamente). El ciclo de refrigeración se repitió hasta no observar ceras precipitadas. Después de filtrar, el extracto etanólico se sometió a un proceso de evaporación al vacío y temperatura de $40^{\circ} \mathrm{C}$, hasta sequedad. La resina obtenida fue envasada en viales ámbar y refrigerada a $-12^{\circ} \mathrm{C}$ hasta posterior utilización.

Propiedades fisicoquímicas. Los análisis se realizaron por triplicado. Los métodos utilizados correspondieron a los reportados en normas internacionales (19), los cuales se describen brevemente: Cenizas; consiste en calcinar una porción de muestra en mufla a $500^{\circ} \mathrm{C}$, y llevar a peso constante. La norma fija un contenido máximo del $5 \%$. Humedad; se determinó mediante método termogravimétrico, que consiste en secar una porción de muestra en estufa a $105 \pm 2{ }^{\circ} \mathrm{C}$, y llevar a peso constante. La norma establece un contenido máximo del $10 \%$. Extractables en éter; se realizó por gravimetría del residuo obtenido mediante una extracción con éter de petróleo $\left(40-60^{\circ} \mathrm{C}\right)$ en un equipo Soxhlet, durante $8 \mathrm{~h}$, posterior destilación del solvente y secado del extracto en estufa a $105^{\circ} \mathrm{C}$ hasta peso constante. Se establece un contenido máximo del $40 \%$. Extractables en etanol; se determinó por gravimetría de las resinas obtenidas mediante una extracción con alcohol etílico ( $96 \%)$, en un Soxhlet, a partir del residuo sólido obtenido en el dedal después de determinar el material extractable con éter de petróleo. Posteriormente se destiló el alcohol a presión reducida y la resina obtenida se secó en estufa a $105^{\circ} \mathrm{C}$; se llevó a peso constante. Se define un contenido mínimo del 30\%. Material insoluble; después de la extracción con etanol, el residuo remanente en el dedal se secó en una estufa a $40^{\circ} \mathrm{C}$ hasta peso constante. La norma plantea para este parámetro un máximo del $25 \%$. Puntos de fusión; se determinó en un fusiómetro Fischer Scientific. Índice de oxidación; se realizó de acuerdo con la metodología descrita por Salamanca et al (20), con algunas modificaciones. Se pesó $0.2 \mathrm{~g}$ de propóleo en un frasco ámbar con tapa; posteriormente se adicionó $3 \mathrm{~mL}$ de etanol destilado (96\%) y se dejó en agitación por $48 \mathrm{~h}$ a $25^{\circ} \mathrm{C}$. La mezcla obtenida se filtró lentamente a través de un papel de filtro. Seguidamente, se tomó $1 \mathrm{~mL}$ del filtrado y se diluyó con agua destilada hasta $25 \mathrm{~mL}$ en un balón aforado. De esta disolución se vertieron $0.5 \mathrm{~mL}$ a un tubo de ensayo, se adicionó $0.5 \mathrm{~mL}$ de agua destilada y $1 \mathrm{~mL}$ de $\mathrm{H}_{2} \mathrm{SO}_{4}$ al $20 \%$ y se agitó durante $1 \mathrm{~min}$. Seguidamente se añadió $50 \mu \mathrm{L}$ de solución de $\mathrm{KMnO}_{4}(0.1 \mathrm{~N})$. El índice de oxidación se reportó como el tiempo de decoloración de la solución del $\mathrm{KMnO}_{4}$ medido en segundos. Las pruebas se realizaron a temperatura ambiente y por triplicado. Absorbancia específica del espectro UV-Vis; se obtuvo para el extracto etanólico por el método de Miyataka et al (21). El espectro de absorción UV-Vis y la absorbancia a la longitud de onda de máxima absorción $(\lambda \max )$, a partir de la cual se calculó el valor $\left(E_{1 \%}^{1 \%}\right)$, se midieron en un espectrofotómetro Shimadzu UV 1800. Los extractos etanólicos del propóleos al $1 \%$ fueron diluidos con etanol del $95 \%$ hasta obtener soluciones en el rango de absorbancia de 1 a 2.5 unidades.

Perfil cromatográfico. El análisis por cromatografía de gases-espectrometría de masas (CG-EM) se realizó en un cromatógrafo de gases Varian 3800 acoplado a un detector de masas Saturn 2000 (tipo trampa de iones). La separación se llevó a cabo en una columna HPS-MS (30 m x $0.25 \mathrm{~mm} \times 0.25 \mu \mathrm{m}$, Agilent Technologies). Las muestras de propóleos, previo al análisis, fueron derivatizadas (metilación) usando el método descrito por Markham et al (22); una alícuota de $400 \mu \mathrm{L}\left(10 \mathrm{mg} \mathrm{mL}^{-1}\right)$ del extracto de propóleo, se combinó con una solución de $\mathrm{CH}_{2} \mathrm{~N}_{2}(400 \mu \mathrm{L})$ en un vial de vidrio; la mezcla resultante se refrigeró durante 4 horas para permitir la metilación completa. Un volumen de muestra de $1 \mu \mathrm{L}$ se inyectó y analizó mediante CG-EM. La temperatura inicial de la columna 
fue de $100^{\circ} \mathrm{C}$, la cual se elevó a $280^{\circ} \mathrm{C}$ y se mantuvo por $15 \mathrm{~min}$, siendo $45 \mathrm{~min}$ el tiempo total de análisis. La inyección se realizó en modo splitless a $250^{\circ} \mathrm{C}$. Se utilizó helio como gas de arrastre a un flujo de $1 \mathrm{~mL} \mathrm{~min}-1$. Los picos fueron identificados por comparación con la base de datos Nist 02 .

Actividad antifúngica in vitro. Se empleó el método de la placa perforada. En cajas de Petri estériles (90 mm de diámetro) se adicionó $15 \mathrm{~mL}$ de medio de cultivo (PDA), previamente esterilizado, a una temperatura de $50^{\circ} \mathrm{C}$. Seguidamente, se adicionó el extracto etanólico del propóleo disuelto en un mezcla etanol/tween $(1 \mathrm{~mL} / 0.5 \mathrm{~g})$, a 5 niveles de concentración (50, $100,250,500,1000 \mathrm{mg} / \mathrm{L})$ y se dejó gelificar a temperatura ambiente. Posteriormente, se colocaron inóculos del hongo de $6 \mathrm{~mm}$ de diámetro, en el punto medio de cada caja Petri que contenía el medio de cultivo (PDA) con la cantidad necesaria del extracto a evaluar. Las placas se incubaron 6 días a $25^{\circ} \mathrm{C}$ y se midió en milímetros el diámetro micelial cada $24 \mathrm{~h}$. Adicionalmente, se realizaron los respectivos controles absoluto y solvente. Las cepas de las tres especies de hongos utilizadas (Aspergillus sp., Penicillium sp., Colletotrichum acutatum y $C$. gloesporioides), fueron donadas y caracterizadas morfológicamente por el Laboratorio de Sanidad Vegetal de la Universidad Nacional de Colombia. Para el análisis de los datos se empleó el programa STATGRAPHICS Centurión y se aplicó Análisis de Varianza (ANOVA) con tres factores (tiempo en horas, tipo de hongo y tratamiento). Para los factores que resultaron significativos se analizaron las diferencias de los niveles con la prueba de comparaciones LSD "Diferencia Mínima Significativa". Se utilizó un nivel de confianza del $95 \%$, y un nivel de potencia para detectar diferencias significativas del $85 \%$ en el análisis de varianza. Los tratamientos se realizaron por triplicado. En la tabla 1 se presenta la conformación del diseño experimental.
Tabla 1. Factores y niveles del diseño experimental.

\begin{tabular}{cc}
\hline Factores & Niveles \\
\hline Tiempo (horas) & $24,48,72,96,144,168$ \\
Hongo & $\begin{array}{c}\text { C. acutatum, C. gloeosporiodes } \\
\text { Penicillium sp. Aspergillus sp. } \\
\end{array}$ \\
Tratamiento (ppm) & Blanco absoluto \\
& Blanco etanol/tween \\
\hline
\end{tabular}

Actividad antibacteriana in vitro. La actividad antibacteriana se evaluó por el método de difusión en disco en agar Mueller-Hilton inoculado con la cepa indicadora correspondiente. En la superficie del agar se depositaron discos de papel de filtro de $6 \mathrm{~mm}$ de diámetro y tamaño de poro de $100 \mu \mathrm{m}$ previamente esterilizados. Los discos fueron impregnados con $20 \mu \mathrm{L}$ de la solución etanólica del propóleos y las cajas incubadas durante $18 \mathrm{~h}$ a $37^{\circ} \mathrm{C}$. La actividad se expresó como la diferencia, en milímetros, entre el radio del halo de inhibición y el radio del disco de papel filtro. Adicionalmente, se realizó un control conteniendo sólo etanol. Las cepas indicadoras utilizadas fueron: Salmonella tiphy, Bacillus subtilis, Staphylococcus aureus y Escherichia coli, obtenidas del laboratorio de Microbiología Industrial de la Universidad Nacional de Colombia. Todas las cepas fueron recuperadas en medio $\mathrm{BHI}$ a $37^{\circ} \mathrm{C}$ por $24 \mathrm{~h}$.

\section{RESULTADOS}

Propiedades fisicoquímicas. La extracción del propóleos crudo con etanol se realizó a temperatura ambiente y en la oscuridad con el fin de evitar alteraciones en los metabolitos secundarios presentes en el material. Mediante el enfriamiento a $-20^{\circ} \mathrm{C}$ y centrifugación de la disolución etanólica se logró un refinamiento del extracto, debido a la precipitación de las ceras, las cuales son insolubles en agua y en el solvente de extracción (etanol 96\%) a bajas temperaturas. Los resultados del análisis fisicoquímico para los propóleos colectados en el municipio de Caldas, se presentan en la tabla 2.

Tabla 2. Propiedades fisicoquímicas de los propóleos recolectados en el municipio de Caldas, Antioquia-Colombia.

\begin{tabular}{lccc}
\hline \multicolumn{1}{c}{ Parámetros } & Caldas raspado (CR) & Caldas malla (CM) & Límites de calidad en norma internacional \\
\hline Cenizas (\%) & $0.78 \pm 0.22$ & $4.77 \pm 0.45$ & Máximo $5 \%$ \\
Humedad (\%) & $2.88 \pm 0.18$ & $1.72 \pm 0.04$ & Máximo $10 \%$ \\
Extractable Éter (\%) & $59.31 \pm 0.78$ & $48.27 \pm 1.61$ & Máximo $40 \%$ \\
Extractable EtOH(\%) & $10.44 \pm 1.97$ & $35.92 \pm 2.98$ & Mínimo $30 \%$ \\
Insolubles (\%) & $28.23 \pm 1.87$ & $14.37 \pm 3.37$ & Máximo $25 \%$ \\
Índice de oxidación $(\mathrm{s})$ & $17.75 \pm 2.69$ & $37.93 \pm 4.05$ & $22 \mathrm{~s}$ \\
Rango de fusión $\left({ }^{\circ} \mathrm{C}\right)$ & $66-82$ & $65-80$ & -- \\
\hline
\end{tabular}


El análisis del espectro de absorción UV-Vis para los extractos etanólicos de los propóleos se presenta en la figura 1 . Ambas muestras presentan un perfil de absorción semejante con una banda amplia a longitudes de onda máxima de 296 (CM) y $280 \mathrm{~nm}$ (CR), y un hombro leve a $309 \mathrm{~nm}$. En general, este rango de absorciones se asocia con la presencia de compuestos fenólicos y flavonoides.

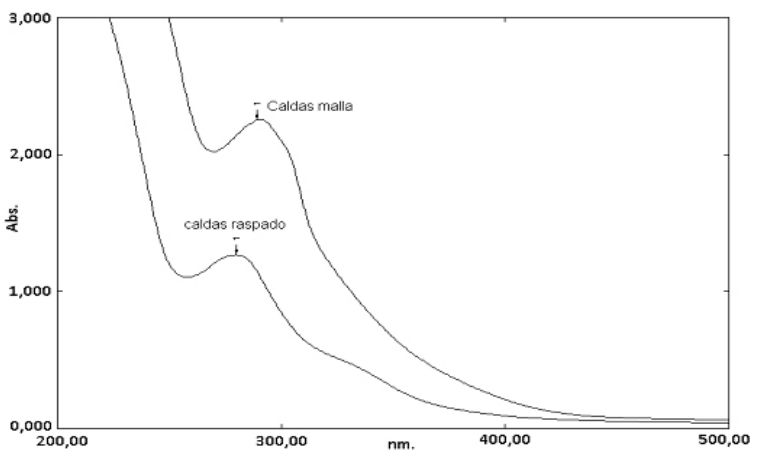

Figura 1. Espectros de absorción de los extractos etanólicos del propóleos de Caldas.

Perfil cromatográfico. A través de la comparación del perfil cromatográfico (GC-MS) se encontró que la muestra CM contiene mayor número de compuestos, y en cantidades relativas superiores, que el extracto CR.

Actividad antifúngica in vitro. La actividad del propóleo para el control de hongos fitopatógenos ha sido poco explorada. Los microorganismos utilizados en los bioensayos se seleccionaron de acuerdo con la incidencia y la importancia económica que estos representan en el departamento de Antioquia. El análisis de varianza para la actividad antifúngica de los propóleos obtenidos en el municipio de caldas (CM y CR), presenta diferencias significativas $(p<0.05)$ en cuanto a la inhibición del crecimiento, el tipo de hongo, el tratamiento aplicado (100-1000ppm) y las respectivas interacciones. Ambos extractos de propóleos mostraron la mayor actividad antifúngica contra los hongos $C$. acutatum y Penicillium sp., para todas las concentraciones y durante las 168 horas de evaluación (Tabla 3).
Tabla 3. Comparaciones múltiples (LSD) del crecimiento microbiano según el tipo de hongo y de propóleo.

\begin{tabular}{lc}
\hline Hongo (propóleo evaluado) & $\begin{array}{c}\text { Crecimiento micelial } \\
(\mathbf{m m}) *\end{array}$ \\
\hline Penicillium sp. (Caldas Malla) & $23.65 \pm 0.15^{\mathrm{a}}$ \\
Penicillium sp. (Caldas Raspado) & $23.90 \pm 0.15^{\mathrm{a}}$ \\
C. acutatum (Caldas Malla) & $23.65 \pm 0.15^{\mathrm{a}}$ \\
C. acutatum (Caldas Raspado) & $25.50 \pm 0.15^{\mathrm{b}}$ \\
C. gloeosporiodes (Caldas Malla) & $31.38 \pm 0.15^{\mathrm{c}}$ \\
C. gloeosporiodes (Caldas Raspado) & $39.90 \pm 0.15^{\mathrm{e}}$ \\
Aspergillus sp. (Caldas Malla) & $31.79 \pm 0.15^{\mathrm{c}}$ \\
Aspergillus sp. (Caldas Raspado) & $35.19 \pm 0.15^{\mathrm{d}}$ \\
\hline
\end{tabular}

* Letras diferentes indican diferencias significativas $(p<0.05)$ según la prueba de diferencias mínimas significativas (LSD).

Para todos los hongos, el propóleo CM presentó diferencias significativas sobre el crecimiento del microorganismo respecto al tratamiento con CR (a la misma concentración) y a los controles absoluto y solvente (Tabla 4).

Tabla 4. Comparaciones múltiples (LSD) del crecimiento microbiano según la concentración y el tipo de propóleo.

\begin{tabular}{lc}
\hline \multicolumn{1}{c}{$\begin{array}{c}\text { Tratamiento }(\boldsymbol{\mu g} / \mathbf{m L}) \mathbf{y} \\
\text { Propóleos }\end{array}$} & Crecimiento $(\mathbf{m m}) *$ \\
\hline 1000 (Caldas Malla) & $24.81 \pm 0.26^{\mathrm{a}}$ \\
500 (Caldas Malla) & $25.35 \pm 0.26^{\mathrm{a}}$ \\
250 (Caldas Malla) & $26.65 \pm 0.26^{\mathrm{b}}$ \\
100 (Caldas Malla) & $26.57 \pm 0.26^{\mathrm{b}}$ \\
1000 (Caldas Raspado) & $28.43 \pm 0.26^{\mathrm{C}}$ \\
500 (Caldas Raspado) & $29.58 \pm 0.26^{\mathrm{d}}$ \\
250 (Caldas Raspado) & $29.92 \pm 0.26^{\mathrm{d}}$ \\
100 (Caldas Raspado) & $30.72 \pm 0.26^{\mathrm{e}}$ \\
Control solvente (Caldas Malla) & $30.96 \pm 0.26^{\mathrm{e}}$ \\
Control absoluto (Caldas Malla) & $31.82 \pm 0.26^{\mathrm{f}}$ \\
Control solvente (Caldas Raspado) & $33.85 \pm 0.26^{\mathrm{g}}$ \\
Control absoluto (Caldas Raspado) & $34.24 \pm 0.26^{\mathrm{g}}$ \\
\hline
\end{tabular}

* Letras diferentes por fila indican diferencias significativas $(p<0.05)$, según la prueba de diferencias mínimas significativas (LSD).

Actividad antibacteriana in vitro. Las zonas de inhibición del crecimiento microbiano con la fracción extractable en EtOH de los propóleos del municipio de Caldas, se presentan en la tabla 5.

Tabla 5. Actividad antibacteriana del propóleos recolectado en el municipio de Caldas, Antioquia-Colombia.

\begin{tabular}{|c|c|c|c|c|c|}
\hline \multirow{2}{*}{ Extracto etanólico del propóleo } & \multirow{2}{*}{ Concentración $(\mathrm{mg} / \mathrm{mL})$} & \multicolumn{4}{|c|}{ Inhibición (mm) } \\
\hline & & S. aureus & B. subtilis & E. coli & S. tiphy \\
\hline \multirow[t]{3}{*}{$\mathrm{CM}$} & 0.1 & $2.00 \pm 0.58$ & - & $3.00 \pm 1.53$ & $4.00 \pm 0.58$ \\
\hline & 1 & $2.00 \pm 1.53$ & - & $6.00 \pm 0.58$ & $5.00 \pm 0.00$ \\
\hline & 10 & $5.00 \pm 1.15$ & $9.00 \pm 0.58$ & $6.00 \pm 1.15$ & $5.00 \pm 0.58$ \\
\hline \multirow[t]{3}{*}{$\mathrm{CR}$} & 0.1 & $3.00 \pm 0.58$ & - & $6.00 \pm 1.00$ & $5.00 \pm 1.00$ \\
\hline & 1 & $3.00 \pm 0.58$ & - & $6.00 \pm 1.15$ & $5.00 \pm 0.00$ \\
\hline & 10 & $3.00 \pm 0.58$ & - & $5.00 \pm 0.58$ & $6.00 \pm 0.58$ \\
\hline Control & - & $3.00 \pm 0.58$ & - & $6.00 \pm 1.15$ & $6.00 \pm 0.58$ \\
\hline
\end{tabular}




\section{DISCUSIÓN}

Propiedades fisicoquímicas. Se observó que ambos propóleos presentaron bajos contenidos de humedad y se encuentran dentro de los límites establecidos por normas internacionales $(10 \%)$. Sin embargo, la humedad del propóleo CR es superior a la encontrada en la muestra CM. Un mayor contenido de humedad es un factor desfavorable si se tiene en cuenta que pueden ser condiciones propicias para el desarrollo de algunas especies de mohos y de fermentaciones durante el almacenamiento de las muestras crudas. El contenido de cenizas es mayor en el propóleos CM; no obstante, los valores para ambos propóleos son inferiores al $5 \%$, que es el máximo permitido de acuerdo con la norma internacional (19). La determinación del contenido de cenizas es particularmente importante para las muestras crudas de propóleos, ya que puede indicar la existencia de un alto contenido de impurezas mecánicas como madera, tierra, fragmentos vegetales, insectos, entre otros, o una posible adulteración del material bruto mediante la adición de impurezas (23).

El contenido de ceras en ambos propóleos superó el límite establecido por la norma de Brasil (máximo 40\%), siendo superior en el material colectado mediante raspado (CR). Un alto contenido de ceras, en muestras de propóleos crudo, es desfavorable porque en esta fracción no se encuentran presentes los compuestos fenólicos, que son los metabolitos secundarios a los cuales se asocia la actividad biológica. Además del contenido de ceras, otro parámetro que influye notablemente en la calidad del propóleos es el contenido de resina soluble en etanol. Cuanto mayor sea el valor de esta fracción mejor será, en términos de rendimiento, la calidad del producto final, puesto que es allí donde se encuentran los compuestos con actividad biológica (24). En los propóleos evaluados se encontró que el límite establecido para el contenido de sustancias extractables con etanol (resina) sólo se alcanza para CM; en éste, el valor es aproximadamente tres veces mayor (35.92 \pm 2.98$)$ que en el propóleos obtenido por raspado (10.44 \pm 1.97$)$.

El bajo contenido de sustancias extractables en etanol posiblemente esté asociado a que las especies vegetales circundantes a la colmena no son muy ricas en resinas con sustancias fenólicas (12); o que durante la recolección, especialmente por el método de raspado, se presente un manejo poscosecha inapropiado por parte del apicultor, mezclando el propóleo con ceras e impurezas mecánicas inherentes al proceso. Lo anterior, estaría en concordancia con los altos valores obtenidos de sustancias extractables en éter de petróleo para ambos propóleos y el mayor contenido de impurezas mecánicas en la muestra CR. Del mismo modo que ocurre con las ceras, las impurezas mecánicas no contienen principios activos, depreciando el valor biológico del producto; valores superiores al $25 \%$ reflejan una baja pureza del propóleo (24). Sin embargo, a pesar del alto contenido de sustancias extractables en éter de petróleo y la baja proporción de resinas, el propóleo CR presentó un índice de oxidación inferior al valor máximo establecido en la norma (22 s). A partir de la información se puede deducir que el propóleos CR posee una buena cantidad de compuestos oxidables; a mayor concentración de este tipo de compuestos menor tiempo de decoloración y por lo tanto mejor calidad del producto en aplicaciones como antioxidante o antiinflamatorio.

De otro lado, el propóleo obtenido mediante malla presentó un índice de oxidación mayor que $22 \mathrm{~s}$; lo anterior, puede ser el resultado de la presencia de algunos metabolitos que pueden modificar la respuesta esperada y confieren propiedades diferentes al producto, como ha sido reportado por Souza et al (25) para muestras con tiempos de oxidación atípicos. El punto de fusión de la muestra es bajo y se encuentra en el rango determinado frecuentemente para propóleos (60$\left.100^{\circ} \mathrm{C}\right)(12)$.

Por su parte, el valor $E_{1 \% n}^{1 \%}$ es un parámetro ampliamente utilizado para evaluar los propóleos, ya que se relaciona con algunas de las actividades biológicas y la presencia de compuestos fenólicos. La intensidad de la absorción a $\lambda$ max en el propóleo CM $\left(E_{1 \% n}^{1 \%}=250.8\right)$ es mayor que en $\operatorname{CR}\left(E_{1 \% n}^{1 \%}=140.8\right)$, lo que denota una concentración cualitativamente superior de compuestos fenólicos en el propóleos obtenido por trampa. Palomino et al (8) reporta una diferencia similar en el valor $E_{10 \%}^{1 \%}$ de muestras colectadas en el mismo apiario, la cual correlacionó positivamente con el contenido de fenoles y flavonoides totales, y la actividad inhibidora de radicales y antioxidante in vitro.

Perfil cromatográfico. En particular, CM exhibió la presencia de diterpenos tipo labdano tales como: 13-epi manool, ácido cummunico, esclareol, ácido isopimárico, ácido agatólico, agatadiol, 13-epi-torulosol; además del totarol y una isoflavona. Por su parte, en el extracto de CR se observó la presencia de esteres metílicos de ácidos grasos como el palmítico, linoléico, oleico y esteárico; además de manool, ácido cummunico, ácido isopimárico y ácido abiético. La presencia de diterpenos tipo labdano ha 
sido reportada recientemente en propóleos colombianos (26), griegos (27) y sicilianos (28). Diferentes plantas han sido mencionadas por estos autores como posible fuente de los propóleos (Cupressus sempervirens y Pinus sp.), destacándose las especies Pinaceae y Cupressaceae que corresponden con la vegetación predominante (Pinus patula, Cupressus lusitánica Miller) cercana a los apiarios de donde se colectó la muestra.

Actividad antifúngica in vitro. Se determinó, para todos los microorganismos, que los menores crecimientos corresponden al tratamiento con $\mathrm{CM}$; presentando, en comparación con CR, diferencias significativas en el crecimiento de los hongos, a excepción de Penicillium sp. Los extractos etanólicos de los propóleos evaluados son relativamente más eficientes en el control de hongos fitopatógenos respecto a aquellos de origen Nigeriano, los cuales presentaron inhibiciones del crecimiento micelial del hongo Colletotrichum lindemutianum a concentraciones mayores al 5\% (29). Adicionalmente, se encontró que el crecimiento radial para todos los hongos es dependiente de la concentración del extracto; un aumento en la concentración incrementa la inhibición del crecimiento micelial. Particularmente, el propóleo CM tiene el mayor efecto inhibitorio sobre el crecimiento de los hongos evaluados a los niveles de concentración empleados (Tabla 4). Las diferencias en la actividad antifúngica posiblemente estén asociadas a una mayor concentración de los metabolitos bioactivos tipo diterpénico, flavonoide y fenólico presentes en el extracto CM (9), como lo confirman el perfil cromatográfico y el espectro de absorción UV-Vis.

Actividad antibacteriana in vitro. $L a$ acción antibacteriana fue dependiente de la concentración, tipo de propóleos y de la especie evaluada. En general, las bacterias E. coli, S. tiphy y $S$. aureus no fueron sensibles al efecto de los propóleos evaluados, presentándose en todo el rango de concentraciones, inhibiciones semejantes al control. No obstante, el extracto etanólico del propóleo colectado por trampa (CM) presentó un efecto bacteriostático a 1.0 $\mathrm{mg} / \mathrm{mL}$ y bactericida a $10 \mathrm{mg} / \mathrm{mL}$, con un halo de inhibición de $9 \pm 0.58 \mathrm{~mm}$ (Figura 2) contra la bacteria esporulada $B$. subtilis.

Es importante mencionar que $B$. subtilis ha demostrado resistencia a algunos antibióticos en el pasado. El extracto del propóleos CR, no presentó inhibición sobre esta bacteria bajo las condiciones de evaluación, lo que indica una baja concentración de metabolitos antibacterianos.

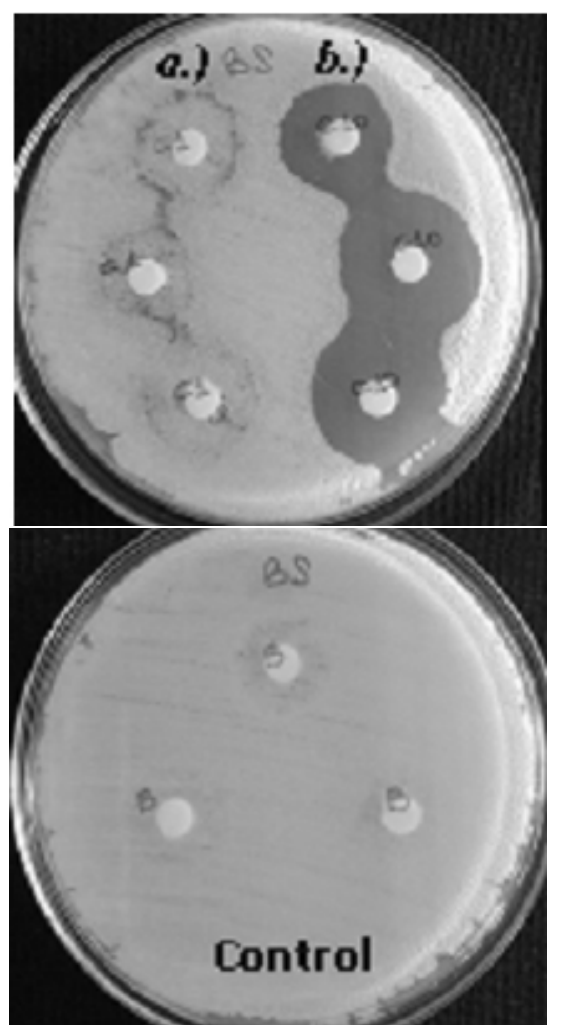

Figura 2. Efecto bacteriostático y bactericida del extracto etanolico de los propóleos del municipio de Caldas contra $B$. subtilis; a) $1 \mathrm{mg} / \mathrm{mL}$ y b) $10 \mathrm{mg} / \mathrm{mL}$.

Los resultados de la actividad antibacteriana concuerdan con aquellos reportados por Sforcin et al (30), quienes observaron una marcada acción de los propóleos contra bacterias Gram-positivas (por ejemplo, B. subtilis) y una actividad limitada contra aquellas Gramnegativas (por ejemplo, E. coli y S. tiphy). Es conocido que bacterias Gram-negativas como E. coli, poseen una membrana adicional denominada "Estructura OM" la cual les confiere un mayor grado de resistencia a los agentes antimicrobianos. Es necesario, sin embargo, evaluar el efecto de los propóleos de Caldas en un número mayor de cepas bacterianas.

En conclusión, las propiedades físico-químicas de los propóleos recolectados en el municipio de Caldas por los dos procedimientos (raspado y malla) presentaron variaciones en las características evaluadas. La muestra que más se ajustó a los parámetros de calidad internacional fue la recolectada por el método de malla. También se observó que los extractos etanólicos de propóleos provenientes del municipio de Caldas (Antioquia) son una fuente potencial de sustancias con actividad antifúngica y antibacteriana; encontrándose 
que el material recolectado por el método de malla presentó el mayor efecto inhibitorio en el crecimiento de los hongos fitopatógenos y de la bacteria $B$. subtilis. Los resultados obtenidos en este estudio complementan estudios previos, con relación a que los propóleos obtenidos por el método de malla matrizada exhiben mejores características fisicoquímicas y biológicas, que los propóleos obtenidos por raspado; por lo tanto, se sugiere que los apicultores utilicen trampas para obtener materiales de mejor calidad, exentos de impurezas y contaminantes. Sin embargo, es necesario realizar estudios sistemáticos complementarios que permitan obtener mayor información relacionada con el efecto del método de recolección de propóleos sobre la calidad del mismo. Actualmente, se están adelantando trabajos en esta dirección.

\section{Agradecimientos}

A la Universidad Nacional de Colombia a través de la dirección de investigaciones para la realización de esta investigación.

1. Paulino N, Abreu SR, Uto $\mathrm{Y}$, Koyama

\section{REFERENCIAS}

$D$, Nagasawa $H$, Hori $H$ et al. Antiinflammatory effects of a bioavailable compound, Artepillin C Brazilian propolis. Eur J Pharmacol 2008; 587: 296-301.

2. Girgin G, Baydar T, Ledochowski M, Schennach $\mathrm{H}$, Bolukbasi DN, Sorkun $\mathrm{K}$ et al. Immunomodulatory effects of Turkish propolis: Changes in neopterin release and tryptophan degradation. Immunobiology 2009; 214:129-134.

3. Banskota M, Tesuka Y, Adnyana I, Ashi E. Hepatoprotective and anti-Helicobacter pylori activities of constituents from Brazilian propolis. Phytomedicine 2009; 8:16-23.

4. Libério $S$, Pereira $A$, Araújo MJA, Dutra RP, Nascimento FRF, Monteiro-Neto V, et al. The potential use of propolis as a cariostatic agent and its actions on mutans group streptococci. J Ethnopharmacol 2009; 125:1-9.

5. Ozkul Y. The anticarcinogenic effect of propolis in human lymphocytes culture. Phytomedicine 2005; 12:742-747.

6. Koru O, Toksoy F, Acikel $\mathrm{CH}$, Tunca YM, Baysallar M, Uskudar GA, et al. In vitro antimicrobial activity of propolis samples from different geographical origins against certain oral pathogens. Anaerobe 2007; 13:140-145.

7. Amoros M, Sauvager F, Girre L, Cormier M. In vitro antiviral activity of propolis. Apidologie 1992; 23: 231-240.

8. Palomino LR, García C M, Gil JH, Rojano BA,
Durango DL. Determinación del contenido de fenoles y evaluación de la actividad antioxidante de propóleos recolectados en el departamento de Antioquia (Colombia). Vitae 2009; 16:388-395.

9. Quiroga EN, Sampietro DA, Soberón JR, Sgariglia MA, Vattuone MA. Propolis from the northwest of Argentina as a source of antifungal principles. J Appl Microbiol 2006; 101:103-110.

10. Peña RC. Estandarización en propóleos: antecedentes químicos y biológicos. Cien Inv Agr 2008; 35:17-26.

11. Alexander C. Propolis: creating a buzz as a natural preservative. Food Eng Ingred 2007; 32:9-11.

12. Chaillou L L, Maidana J. Estudio del propóleos de Santiago del Estero, Argentina. Ciênc Tecnol Aliment 2004; 24:11-15.

13. Kalogeropoulos N, Konteles SJ, Troullidou E, Mourtzinos I, Karathanos VT. Chemical composition, antioxidant activity and antimicrobial properties of propolis extracts from Greece and Cyprus. Food Chem 2009; 116: 452-461.

14. Londoño A, Penieres J, Garcia C, Carrillo L, Quintero M, Garcia S et al. Estudio de la actividad antifúngica de un extracto de propóleo de la abeja Apis mellifera proveniente del estado de México. Tecnología en Marcha 2008; 21-1:49-55.

15. Bankova V. Chemical diversity of propolis 
makes it a valuablesource of new biologically active compounds. Journal of ApiProduct and ApiMedical Science 2009; $1(2): 23-28$.

16. Idarraga H. El propóleo: comparación de diferentes trampas para su cosecha. Carta Apícola 2003; 15 (3):1-16.

17. Sales A, Alvarez A, Areal MR, Maldonado L, Marchisio P, Rodríguez M, Bedascarrasbure $E$. The effect of different propolis harvest methods on its lead contents determined by ET AAS and UV-vis. J Hazard Mater 2006; 137:1352-1356.

18. Lopez $S$, Subovsky MJ, Castillo AE, Ramirez SS, Rolin H, Oviedo B. Calidad de los propoleos de la Provincia de Misiones. Universidad Nacional del Nordeste, Comunicaciones científicas y Tecnologicas. 2000. (Fecha de acceso 1 de diciembre de 2009). URL disponible en: http:// www.unne.edu.ar/Web/cyt/cyt/2000/5_ agrarias/a_pdf/a_030.pdf.

19. Ministério de agricultura de Brasil. Instrução Normativa no 3-ANEXO VIRegulamento técnico para fixação de identidade e qualidade de própolis. Diário Oficial da República Federativa do Brasil. Brasília, 19 jan. 2001 (fecha de acceso 5 de marzo de 2009. Disponible en: http:// www.apacame.org.br/mensagemdoce/60/ normas.htm.

20. Salamanca G, Correa I, Principal J. Perfil de flavonoides e índices de oxidación de algunos propóleos colombianos. Zootecnia Tropical 2007; 25:95-102.

21. Miyataka $H$, Nishiki $M$, Matsumoto $H$, Fujimoto T, Matsuka M, Satoh, T. Evaluation of Propolis I. Evaluation of Brazilian and Chinese Propolis by Enzymatic and Physico-Chemical Methods. Bio Pharm Bull 1997; 20:496-501.

22. Markham KR, Mitchell KA, Wilkins A L, Daldy
J A, Lu Y. HPLC and GC-MS identification of the major organic constituents in New Zealand propolis. Phytochemistry 1996; 42:205-211.

23. Funari C, Ferro V. Análise de própolis. Ciênc Tecnol Aliment 2006; 26:171-178.

24. Arrate L. Propoleo, el "antibiótico" natural de la colmena. Sustrai: Revista Agropesquera 2008; 85:56-61.

25. Souza R, Souza M, Mendes J. Análise de extratos aquosos e etanólicos de própolis por cromatografia líquida de alta eficiência. Memórias 25 Reunião Anual da Sociedade Brasileira de Química 2002.

26. Meneses E A, Durango D, García C M. Antifungal activity against postharvest fungi by extracts from Colombian propolis. Quím Nova 2009; 2:2011-2017.

27. Popova M, Chinou I, Marekov I, Bankova $\mathrm{V}$. Terpenes with antimicrobial activity from Cretan propolis. Phytochemistry 2009; 70:1262-1271.

28. Trusheva B, Popova M. Bankova V, Tsvetkova I, Naydensky C, Sabatini A G. A new type of European propolis, containing bioactive labdanes, Riv Ital EPPOS 2003; $36: 3-7$.

29. Obasa K C, Adeoti A Y, Enikuomehin O A, Bodunde J G. Efficacy Of Bee-Propolis In The Control Of Colletotrichum Lindemutianum (Sacc.And Magn.) Brosi And Cav. In vitro. Res J Microbiol 2007; 2:175-179.

30. Sforcin J M, Fernandes Jr A, Lopes C A, Bankova V, Funari S R C, Seasonal effect on Brazilian propolis antibacterial activity. J Ethnopharmacol 2000; 73: 243-249. 